\title{
GCU
}

Glasgow Caledonian

University

University for the Common Good

\section{Enhanced fault diagnosis of DFIG converter systems}

Ibem, Chukwuemeka N.; Farrag, Mohamed Emad; Aboushady, Ahmed A.

Published in:

2019 54th International Universities Power Engineering Conference (UPEC)

DOI:

10.1109/UPEC.2019.8893567

Publication date:

2019

Document Version

Author accepted manuscript

Link to publication in ResearchOnline

Citation for published version (Harvard):

Ibem, CN, Farrag, ME \& Aboushady, AA 2019, Enhanced fault diagnosis of DFIG converter systems. in 2019 54th International Universities Power Engineering Conference (UPEC). IEEE, pp. 1-6.

https://doi.org/10.1109/UPEC.2019.8893567

\section{General rights}

Copyright and moral rights for the publications made accessible in the public portal are retained by the authors and/or other copyright owners and it is a condition of accessing publications that users recognise and abide by the legal requirements associated with these rights.

Take down policy

If you believe that this document breaches copyright please view our takedown policy at https://edshare.gcu.ac.uk/id/eprint/5179 for details of how to contact us. 


\section{ENHANCED FAULT DIAGNOSIS OF DFIG CONVERTER SYSTEMS}

\author{
Chukwuemeka N Ibem \\ School of Computing, Engineering \\ and Built Environment \\ Glasgow Caledonian University \\ Glasgow, U.K \\ Chukwuemeka.ibem@gcu.ac.uk
}

\author{
Mohamed Emad Farrag \\ School of Computing, Engineering \\ and Built Environment, \\ Glasgow Caledonian University \\ Glasgow, UK. \\ Mohamed.Farrag@gcu.ac.uk
}

\author{
Ahmed A. Aboushady \\ School of Computing, Engineering \\ and Built Environment, \\ Glasgow Caledonian University \\ Glasgow, UK \\ Ahmed.Aboushady@gcu.ac.uk
}

\begin{abstract}
The converter is a crucial part of the doubly fed induction generator (DFIG) wind energy conversion system (WECS). Breakdown of the converter will lead to huge economic loss; this is relating to the downtime of the converter that will shut down the whole turbine-generator system and curtail the energy production. Fault diagnosis is considered a preliminary tool that is used to tackle the possibilities of converter downtime. There are varieties of fault diagnosis techniques and algorithms for different faults types and location. This paper is presenting an enhanced technique based on the possibility of combining the DFIG currentmeasurements and torque to develop a robust FD technique for DFIG converter systems. The results obtained from the simulation phase is encouraging to merge fault indicators from current and torque to identify the fault location and nature at either side of the DFIG converters.
\end{abstract}

Index Terms-Converter, DFIG, Fault diagnosis, Renewable energy, WECS.

\section{INTRODUCTION}

Concerns of the impact of fossil fuel on the environment has led to a rapid growth in the utilization of alternative resources mainly renewable $[1,2]$. Wind energy has emerged as one of the fastest growing renewable source, having an average growth rate of $21 \%$ each year [3]. However, with the rapid increase in the integration of wind energy into existing power systems, new challenges arise. The doubly fed induction generator (DFIG) is one of the most used wind energy conversion system (WECS), not just for its economic viability but also its control flexibility, it provides control of active and reactive power to ensure system stability.

Meanwhile, factors such as remote location and increasing power rate of WECS has resulted in expensive and time consuming maintenance [4]. Reliability of the WECS is key for wind energy integration into the grid. Analysis shows that the power electronics converters are one of the most susceptible part of the WECS to faults and they account for $14 \%$ of the WECS total downtime [*]. Thus, reliability of the power electronic converters is of paramount importance. Condition monitoring and fault tolerant schemes have gained lots of attention recently and are key to increasing reliability. Schemes as such, ensure less power flow interruptions by providing controlled and stable operations. Many research works have been conducted on fault diagnosis of different parts of the WECS, but none developed amalgamated technique to increase the robustness of the fault detection.

Over the years most of fault diagnosis (FD) of converter are used for general applications such as motor drives and electrical storage, this is in contrast with few FD techniques of WECS converters [4]. The conventional FD technique (E.g pack vector and slope method) cannot be implemented directly on the WECS especially the DFIG converter due to its dynamic operation [5,6]. Challenges such as False alarm arises and affect these techniques[5]. The following methods have been applied for open circuit FD on converters for motor drives; authors in [7-9] proposed the use of park vector method, which identifies and locate open circuit fault by monitoring the average current trajectory. For a normal system condition the space vector trajectory is a full circle. The drawback of this method is its load dependency as addressed by Ref [10], it introduces the normalized DC method. The normalized dc current is calculated for each phase and is compared with a threshold (which is a universal standard based on experience) to identify the faulty switch. Pattern recognition method is introduced in [11] where different fault signatures can be characterised by their current waveform patterns in the time domain. Features such as dc component and the average current polarity define these patterns. authors in $[12,13]$ proposed a ccomparison of $\mathrm{AC}$ actual voltage to a reference and expected voltage. For short circuit FD on converters used in motor drives the following methods has been applied; authors in [14,15] proposed short circuit FD method based on sensing the gate voltage of the power electronic devices, IGBT in this study. This method has a fast detection time but its major drawback was the addition of extra voltage sensors to measure the gate voltage of each switch. A recent method using voltage-space patterns analysis was proposed by [16] involves the analysis of the PWM voltage signal. Each phase voltage is represented in 3$\mathrm{D}$ voltage space and their pattern is analysed in time-free space. For normal conditions a cubic shape will be formed in the voltage space. This method shows independency of the waveform from load and transient conditions but extra sensors where deployed to sense the PWM voltages.

Several researches have been conducted on identifying WECS faults either for the PMSG or the DFIG configuration. There is less research works addressing FD on the latter in contrast to the former. For open circuit devices based FD on DFIG converters for motor drives, the following methods has been investigated; Ref [17] proposed absolute normalized DC current method which was derived from the normalized DC current method. The normalized value used is the average phase current instead of the fundamental component used in the previous method. In [18] a technique based on vibration analysis is proposed for the DFIG generator's rotor side converter. An accelerometer was placed on the DFIG generator to extract the vibrations of the 
generator and the vibration is analysed for a healthy and faulty condition.

The major drawbacks in this literature is the generation of false alarm and the addition of more components. False alarms are generated due to the transient nature of the DFIG (i.e. constant variation in the rotor frequency). The addition of component reduces the reliability of the system. Also, research works were focused on developing unique algorithms for specific fault such as open and short circuit fault for different individual part of the DFIG converter (such as the GSC and the RSC). Thus, many fault detection algorithms are used for monitoring various parts of the DFIG converter.

This paper proposes the possibility of having a single fault diagnosis technique for DFIG converter, to differentiate faults and their location and taking false alarms into consideration. It proposes the combination of electromagnetic torque and current for FD for DFIG converters. Results in this paper shows the torque can be used for classification of faults on different locations. It can also be used as a second parameter to confirm faulty conditions to reduce false alarms. The major advantage is reducing the time spent on running different fault diagnosis at different converter locations to identify faults.

\section{DFIG CONFIGURATION}

The DFIG model used in this paper is shown in Fig. 1. It consists of a $1.5 \mathrm{MW}$ wind turbine which delivers power to a $120 \mathrm{kV}$ grid through a $25 \mathrm{kV}$ distribution system. It uses a DFIG generator which consist of a back to back converter (IGBT PWM converter) and a wound rotor induction generator. Its design is a partial DFIG configuration, where the rotor is connected to the back to back converter and then to the grid. Thus, power is fed to the rotor at varying frequencies through the back to back converter. The stator is directly connected to the grid. Parameters used for the model can be seen in Tables A1 and A2 in the Appendix.

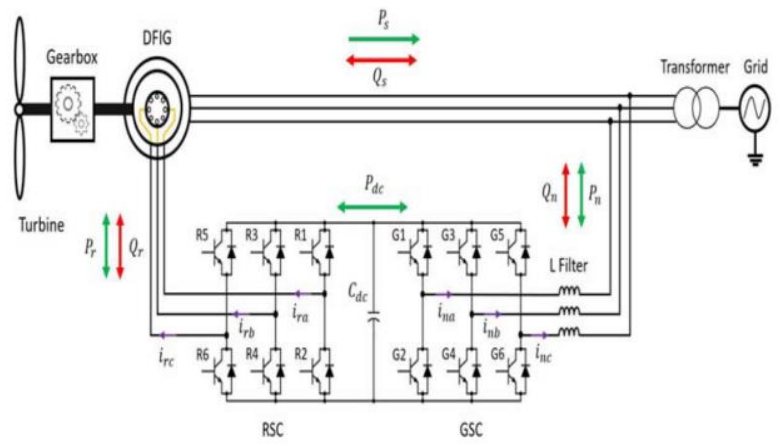

Figure 1 DFIG topology [5]

\section{DFIG D-Q MODEL}

Fig. 2 shows an equivalent DFIG circuit in which the d-q coordinate can be derived. Eq. 1 shows the space vector form of the differential voltage equation for rotor and stator [19].

$$
\begin{aligned}
& V_{s}=I_{s} R_{s}+d \psi_{s} / d t \\
& V_{r}=I_{r} R_{r}+d \psi_{r} / d t
\end{aligned}
$$

The d-q coordinate system at synchronous rotational speed is obtained by converting Eq.1-2 The d-q transformation is shown in Eq. 3-4 [19]

$$
\begin{aligned}
& v_{s d q}=R_{s} I_{s d q}+d \psi_{s d q} / d t+j \omega_{s} \psi_{s d q} \\
& v_{r d q}=R_{s} I_{s d q}+d \psi_{s d q} / d t+j\left(\omega_{s}-\omega\right) \psi_{s d q}
\end{aligned}
$$

Relationship between the $\psi$ and both $\mathrm{I}_{\mathrm{s}}$ and $I_{r}$ is shown in Eq. 5-6 [19]

$$
\begin{aligned}
& \psi_{s}=L_{s} I_{s}+L_{m} I_{r} \\
& \psi_{r}=L_{r} I_{r}+L_{m} I_{s}
\end{aligned}
$$

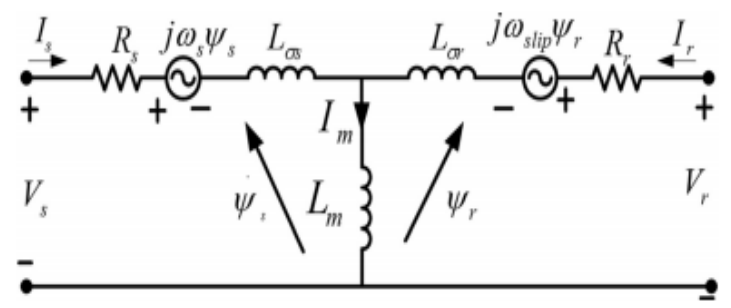

Figure 2 Equivalent circuit of DFIG [20]

where,

$\mathrm{V}_{\mathrm{s}}, \mathrm{V}_{\mathrm{r}}=$ stator and rotor voltages

$I_{s}, I_{r}=$ stator and rotor currents

$\mathrm{Rs}, \mathrm{Rr}=$ Stator and rotor winding resistance

$\mathrm{Ls}, \mathrm{Lr}, \mathrm{Lm}=$ Stator, rotor, and magnetizing leakage inductance $\mathrm{Ws}, \mathrm{Wr}=$ Stator and rotor flux angle

$V_{d r}, V_{q r}=$ Rotor voltage in $d-q$ stator flux reference frame at synchronous speed

\section{A. DFIG elecromagnetic torque}

The electromagnetic torque of the DFIG is regarded as a result of the rotor and stator supply. Time varying electromagnetic field is generated as a result of varying time movement of the rotor as the stator is stationary thus, electromagnetic torque is produced [19]. The torque can be represented in current, voltage and power forms. The common representation is the current representation; this is shown in Eq. 7 [19]

$$
T=\frac{3}{2} p l_{m}\left(I_{r d} I_{s q}-I_{r q} I_{s d}\right)
$$

Where $\mathrm{p}=$ poles

$l_{m}=$ magnetizing inductance

$I_{r d}=$ stator current in the d frame

$I_{s q}=$ stator current in in the $\mathrm{q}$ frame

$I_{r q}=$ rotor current in the $\mathrm{q}$ frame

$I_{s d}=$ stator current in the d frame

\section{MONITORING DFIG CURRENT}

As outlined in the previous section, work in this paper is focusing on the possibility of combining the DFIG torque and current measurement for a robust FD technique for the DFIG system. Thus, it is imperative to analyse and understand these parameters in different faulty conditions to know how much information can be extracted from them. 
In this section, harmonics simulations result of the DFIG current during open circuit (OC) and short circuit (SC) fault at different locations are displayed and analysed. However, Fig. 3 shows the current harmonics during normal conditions.

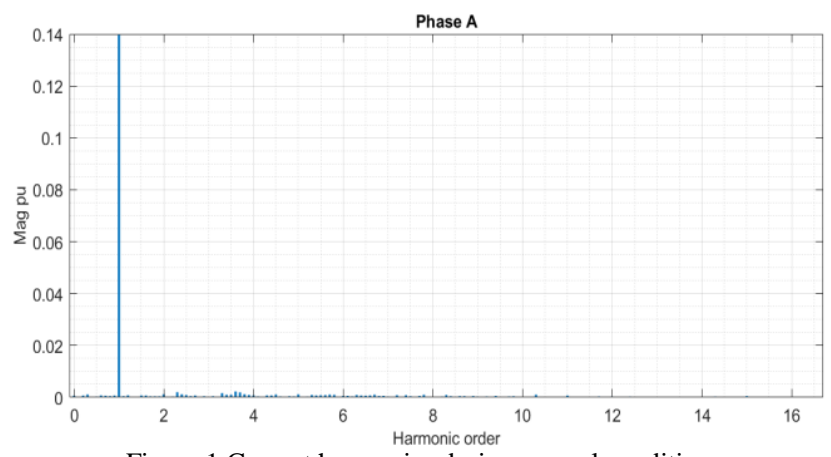

Figure 1 Current harmonics during normal conditions

Current harmonics simulations were conducted for the following fault scenarios;

- Scenario 1: open circuit at the GSC

- Scenario 2; open circuit at the RSC

- Scenario 3; open circuit at the grid connection

- Scenario 4; short circuit at the GSC

- Scenario 5; short circuit at the RSC

- Scenario 6; short circuit at the grid connection

\section{A. Scenario 1}

An OC fault is applied to phase A of the GSC, the harmonics of the current signals can be seen in Fig. 4. It is observed that there is a presence of zero order harmonics compare to the normal conditions. Minimal sidebands are also observed.

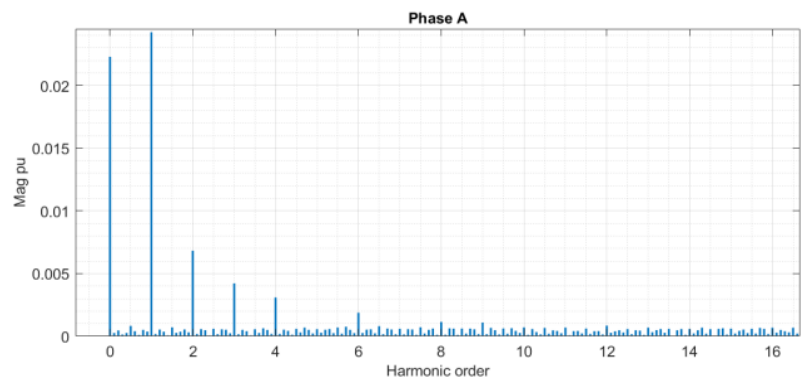

(a) Current in phase $\mathrm{A}$

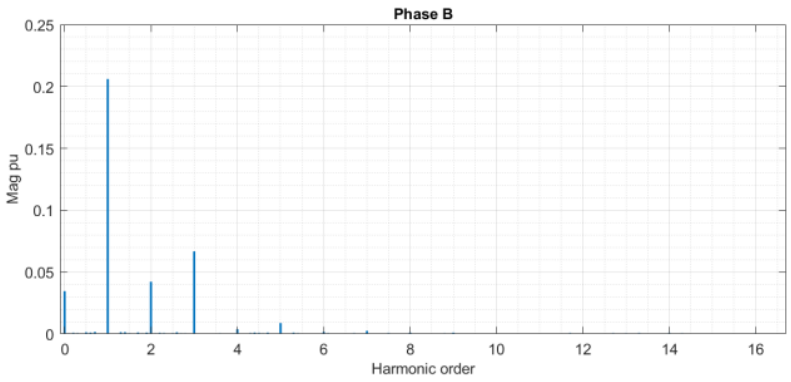

(b) Current in phase B

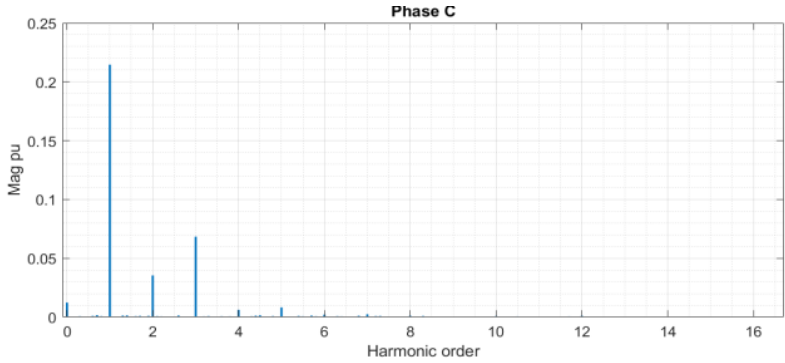

(c) Current in phase $\mathrm{C}$

Figure 2 Open circuit fault on phase A of GSC

\section{B. Scenario 2}

An OC fault is applied to phase A of the RSC, the harmonics of the current signals can be seen in Fig. 5. The result shows the presence of odd and even harmonics in each phase with lots of noise/sidebands.

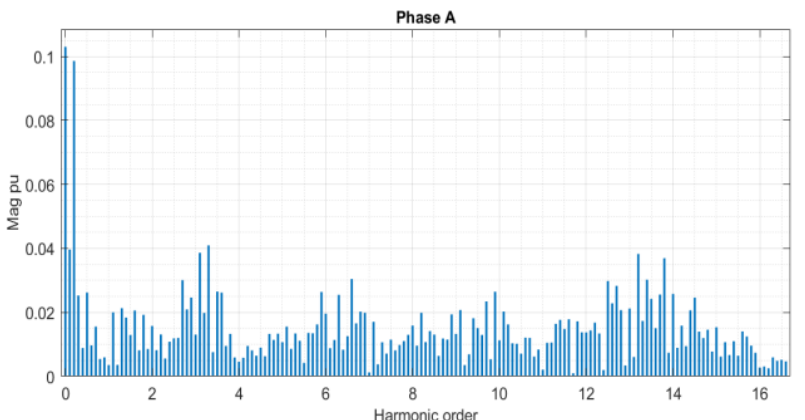

(a) Current in phase A

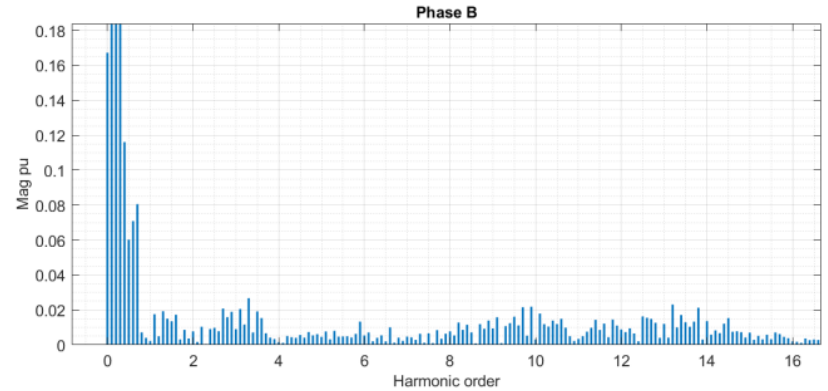

(b) Current in phase B

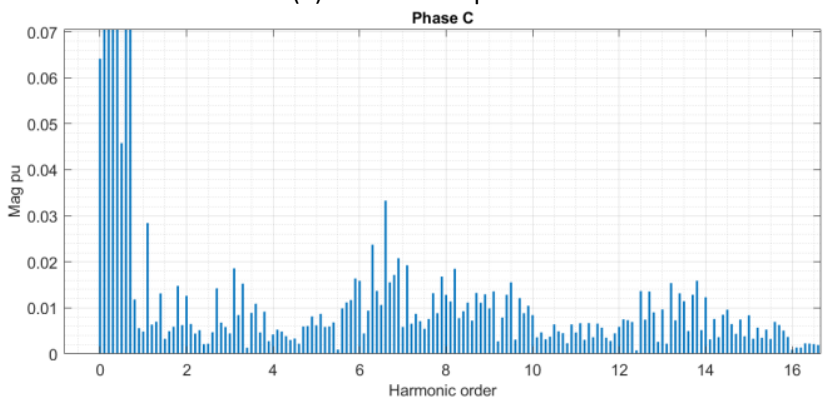

(c) Current in phase $\mathrm{C}$

Figure 3 Open circuit fault on phase A on RSC

\section{Scenario 3}

Fig. 6 shows the currents' harmonic result when an OC fault is applied to phase A of the grid connection. Odd harmonics with no sidebands are dominant in this case. 


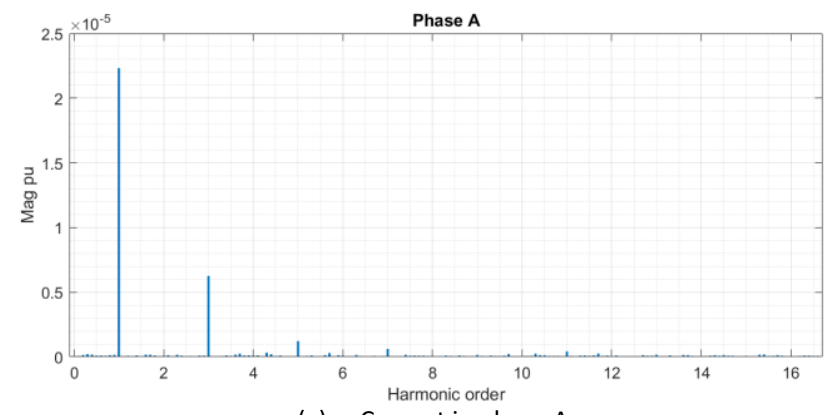

(a) Current in phase A

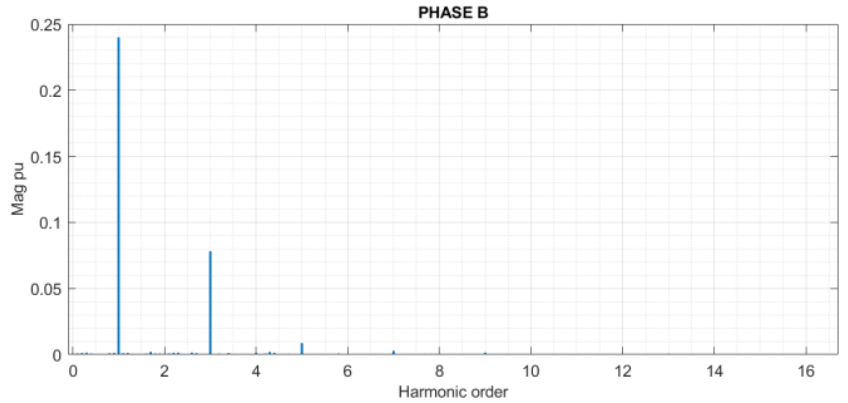

(b) Current in phase B

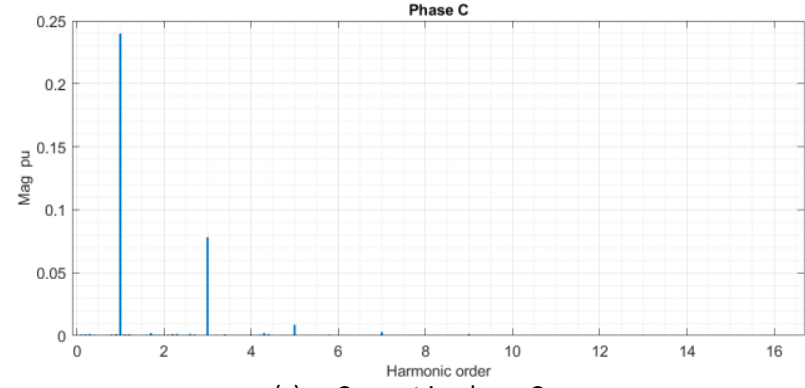

(c) Current in phase $\mathrm{C}$

Figure 4 Currents' harmonics on open circuit fault phase A on the grid

\section{Scenario 4}

A SC fault is applied to phase A of the GSC, the resultant harmonics can be seen in Fig. 7. In this case even harmonics with no side bands were observed.

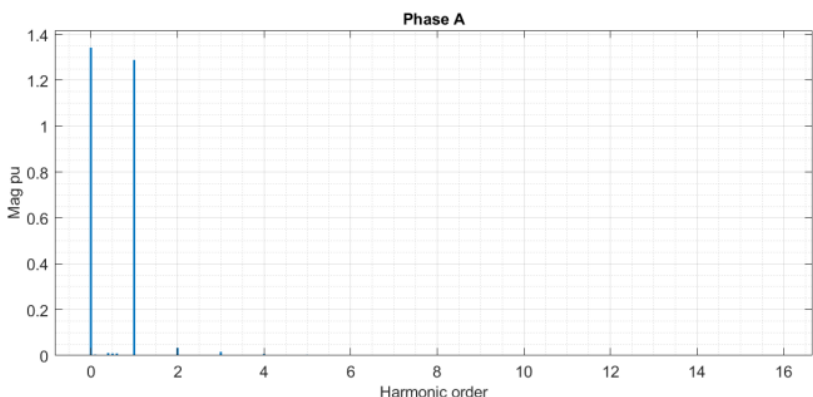

(a) Current in phase $\mathrm{A}$

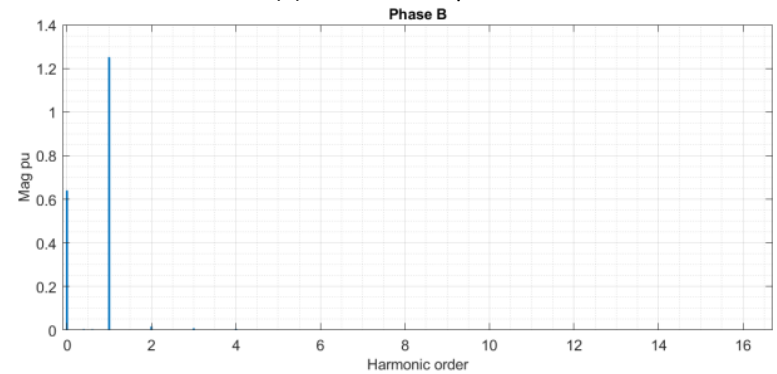

(b) Current in phase B

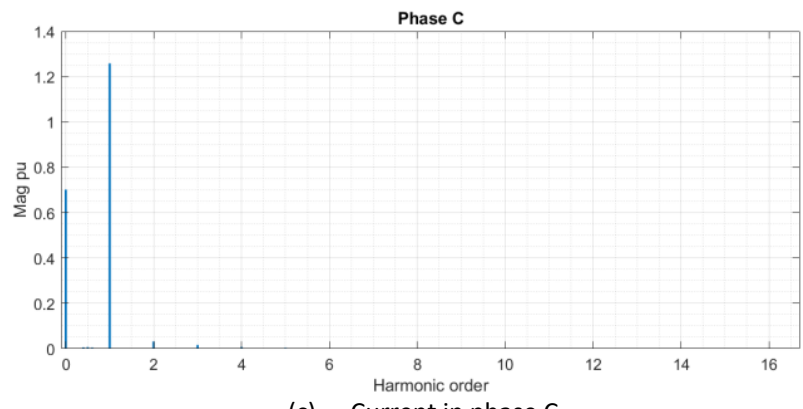

(c) Current in phase C

Figure 5 Short circuit fault on phase A

\section{E. Scenario 5}

A SC fault is applied to phase A of the RSC, the harmonics of the current signals can be seen in Fig. 8. Odd and even harmonics with lots of sidebands were observed.

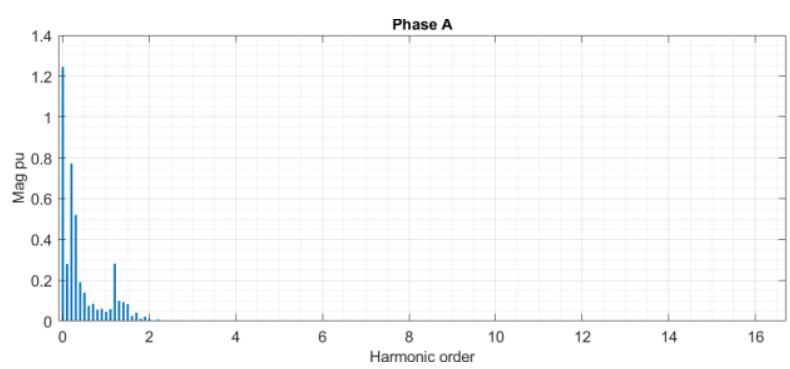

(a) Current in phase $\mathrm{A}$

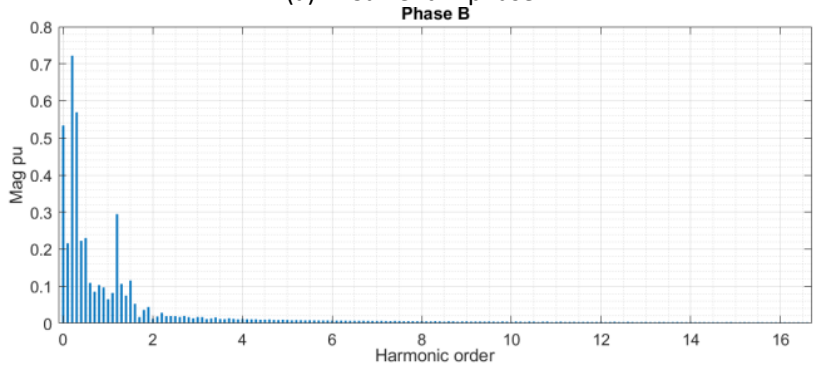

(b) Current in phase $B$

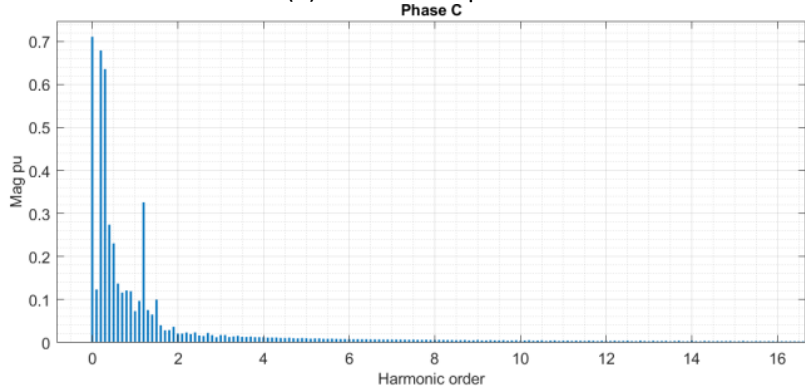

(c) Current in phase $\mathrm{C}$

Figure 6 Short circuit fault phase A on the RSC

\section{MONITORING DFIG TORQUE}

In this section, harmonics simulations result of the DFIG torque during $\mathrm{OC}$ and $\mathrm{SC}$ fault at different locations are shown. Fig. 9 shows the torque harmonics during normal conditions. It is observed that the zero-order harmonic is the only present harmonic. 


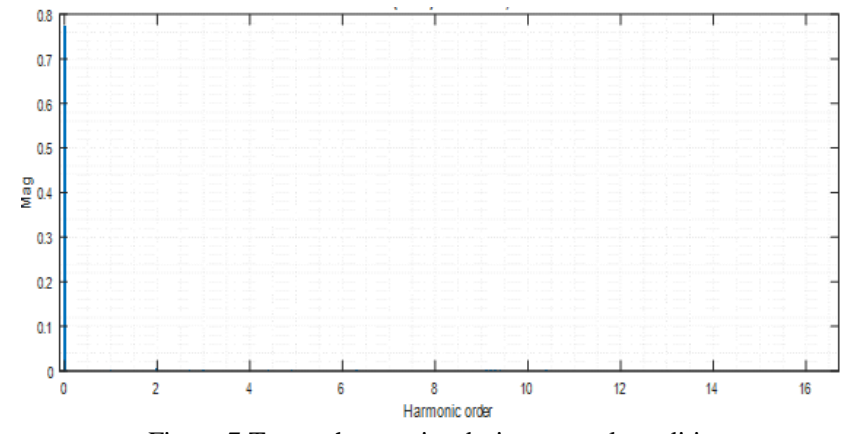

Figure 7 Torque harmonics during normal conditions

\section{A. Scenario 1}

Fig. 10 shows the torque harmonics result when an OC fault is applied to phase A of the GSC. It is observed that the zero order harmonics magnitude is the same as the normal condition and even harmonics are present.

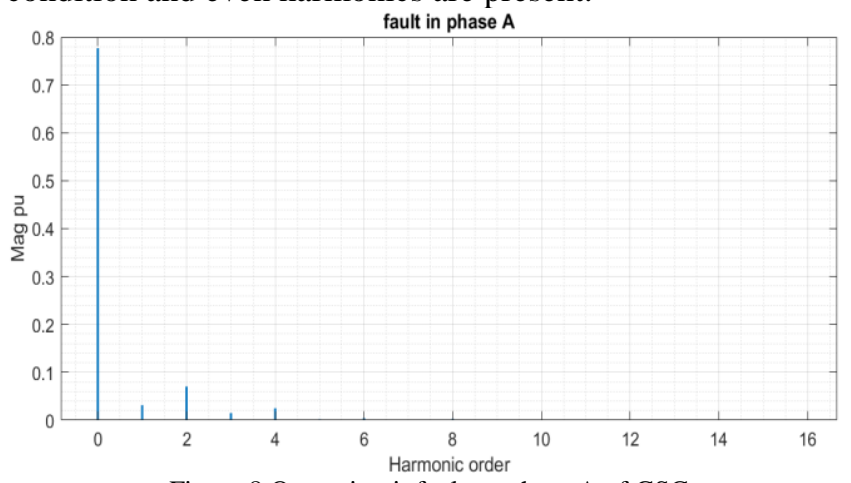

Figure 8 Open circuit fault on phase A of GSC

\section{B. Scenario 2}

An OC fault is applied to phase A of the RSC and its torque harmonics result can be seen in Fig. 11. Lots of sideband can be observed from the result.

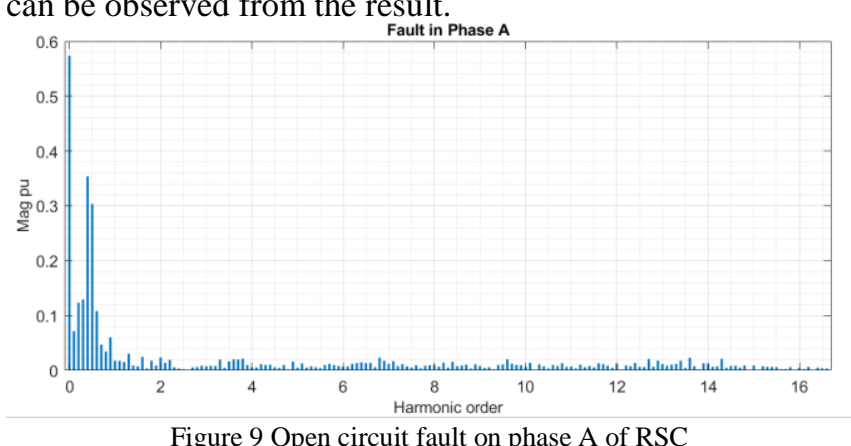

\section{Scenario 3}

Fig. 12 shows the torque harmonics result when an OC fault is applied to phase A of the grid connection. It is observed that the zero order harmonics magnitude is the same as the normal condition and even harmonics are present.

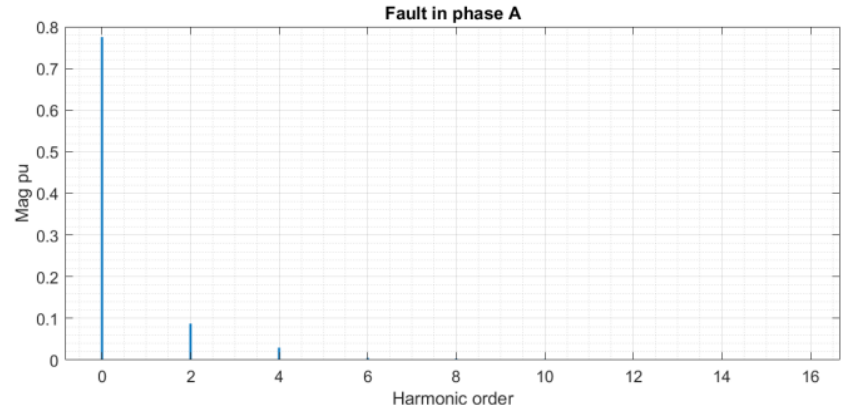

Figure 10 Open circuit fault on phase C

\section{Scenario 4}

Fig. 13 shows the torque harmonics result when an SC fault is applied to phase A of the GSC. It is observed that the zero order harmonics magnitude decreases compared to the normal condition, less sidebands impacts.

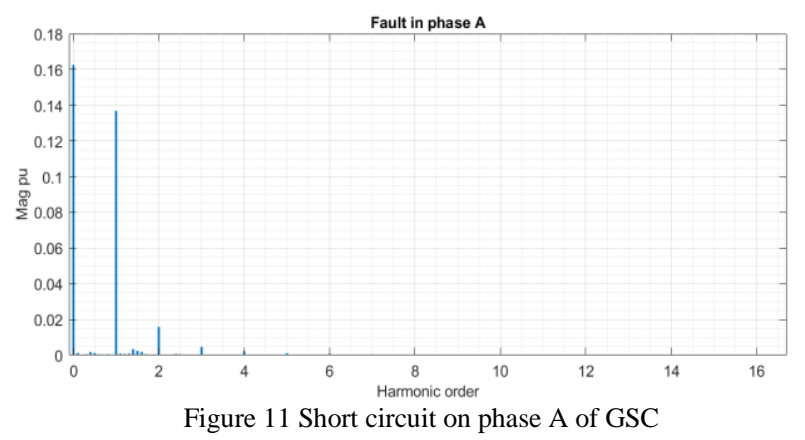

\section{E. Scenario 5}

Fig. 14 shows the torque harmonics result when an SC fault is applied to phase A of the RSC. It is observed that the zero order harmonics magnitude decreases compared to the normal condition. lots of sidebands present.

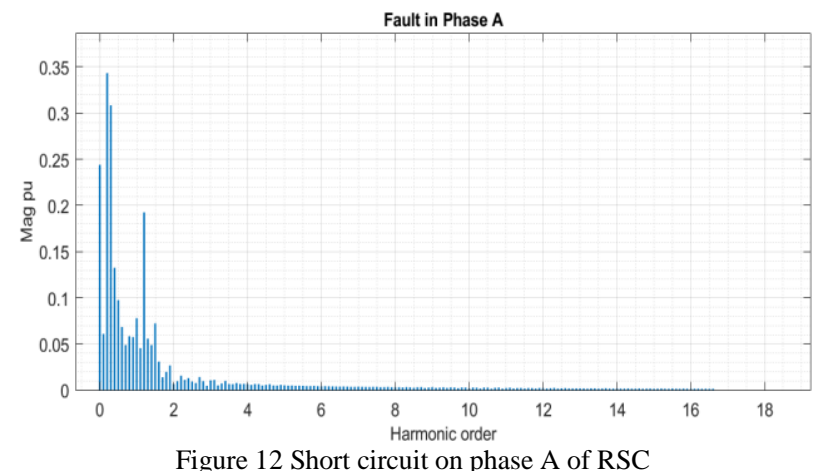

VI. DISCUSSION

Table 1 and 2 shows the observations made from the simulation results in the previous section from Figs. 3-14. It also compares the current and torque harmonics during OC and SC faults at different locations. From the result it is clearly seen that during $\mathrm{OC}$ and SC fault in the RSC and GSC the current harmonics are similar, but the torque harmonics differs. The current harmonics can be used to identify the faulty phase, but the torque harmonics can't. 
TABLE 1. Comparison Of The Torque And Current Analysis During OC

\begin{tabular}{|c|c|l|l|}
\cline { 3 - 4 } \multicolumn{1}{c|}{} & \multicolumn{1}{|c|}{ Current } & \multicolumn{1}{c|}{ Torque } \\
\hline \multirow{2}{*}{$\begin{array}{c}\text { Open } \\
\text { circuit } \\
\text { fault }\end{array}$} & RSC & $\begin{array}{l}\text { Odd and Even harmonics } \\
\text { sidebands/noise } \\
\text { Zero order harmonics } \\
\text { magnitude increased }\end{array}$ & $\begin{array}{l}\text { Even harmonics } \\
\text { Zero order harmonics } \\
\text { magnitude is similar to } \\
\text { normal condition }\end{array}$ \\
\cline { 2 - 4 } & GRID & $\begin{array}{l}\text { Odd and even harmonics } \\
\text { sidebands/noise }\end{array}$ & $\begin{array}{l}\text { Lots of sideband } \\
\text { Zero order harmonics } \\
\text { magnitude increased }\end{array}$ \\
\hline & $\begin{array}{l}\text { Odd harmonics } \\
\text { Faulty phase has a } \\
\text { smaller magnitude } \\
\text { compared to others }\end{array}$ & Even harmonics \\
\hline
\end{tabular}

TABLE 2 Comparison Of The Torque And Current Analysis During SC

\begin{tabular}{|c|l|l|l|}
\cline { 3 - 4 } \multicolumn{2}{c|}{} & Current & Torque \\
\hline \multirow{2}{*}{$\begin{array}{c}\text { Short } \\
\text { circuit } \\
\text { fault }\end{array}$} & GSC & $\begin{array}{l}\text { No sidebands/noise } \\
\text { Even harmonics } \\
\text { Zero order harmonics } \\
\text { magnitude increased }\end{array}$ & $\begin{array}{l}\text { No sidebands or noise on } \\
\text { the harmonics. } \\
\text { Harmonics magnitude } \\
\text { decreases compared to } \\
\text { the normal conditions }\end{array}$ \\
\cline { 3 - 5 } & RSC & $\begin{array}{l}\text { Lots of sidebands/noise } \\
\text { Odd and even } \\
\text { harmonics }\end{array}$ & $\begin{array}{l}\text { Harmonics magnitude } \\
\text { decreases compared to } \\
\text { the normal conditions } \\
\text { Lots of sidebands/noise }\end{array}$ \\
\hline
\end{tabular}

\section{CONCLUSION}

The result has shown that parameters such as the current and torque are affected during faulty conditions and can be used as a fault diagnostic parameter. However, one parameter will not give enough information to develop a robust FD technique for DFIG converters. Future works on this research will be; Validation of the simulation result by developing a test system.

Designing and training a neural network system for different faults based on knowledge on fault signatures.

VIII. APPENDIX

TABLE A1 GENERATOR PARAMETERS

\begin{tabular}{|l|l|}
\hline \multicolumn{2}{|c|}{ TABLE A1 GENERATOR PARAMETERS } \\
\hline Parameters & Values \\
\hline Nominal power & $672 \mathrm{VA}$ \\
\hline Stator line to line voltage & $575 \mathrm{~V}$ \\
\hline Rotor line to line voltage & $1975 \mathrm{~V}$ \\
\hline Frequency & $60 \mathrm{HZ}$ \\
\hline Stator reactance & $0.023 \mathrm{P} . \mathrm{U}$ \\
\hline Stator inductance & $0.18 \mathrm{P} . \mathrm{U}$ \\
\hline Rotor reactance & $0.016 \mathrm{P} . \mathrm{U}$ \\
\hline ROTOR INDUCTANCE & $0.16 \mathrm{P} . \mathrm{U}$ \\
\hline Magnetizing inductance & $2.9 \mathrm{P} . \mathrm{U}$ \\
\hline Slip & -0.2 \\
\hline Poles & 6 \\
\hline
\end{tabular}

TABLE A2 CONVERTER PARAMETERS

\begin{tabular}{|l|l|}
\hline Parameters & Values \\
\hline DC bus capacitor voltage & $1150 \mathrm{~V}$ \\
\hline DC bus capacitor & $10000 \mathrm{e}-6$ \\
\hline IGBT internal resistance & $1 \mathrm{e}-3 \mathrm{ohms}$ \\
\hline
\end{tabular}

\section{REFERENCES}

[13] Z Li, H. Ma, Z Bai, Y. Wang, B. Wang, Fast Transistor OpenCircuit Faults Diagnosis in Grid-Tied Three-Phase VSIs Based on Average Bridge Arm Pole-to-Pole Voltages and ErrorAdaptive Thresholds, IEEE Trans. Power Electron. 33 (2018) 8040-8051. doi:10.1109/TPEL.2017.2773130.

[14] M.A. Rodríguez, A. Claudio, D. Theilliol, L.G. Vela, A new fault detection technique for IGBT based on gate voltage monitoring, PESC Rec. - IEEE Annu. Power Electron. Spec. Conf. (2007) 1001-1005. doi:10.1109/PESC.2007.4342127.

[15] M.A. Rodríguez-Blanco, A. Claudio-Sánchez, D. Theilliol, L.G. Vela-Valdés, P. Sibaja-Terán, L. Hernández-González, J. Aguayo-Alquicira, A failure-detection strategy for IGBT based on gate-voltage behavior applied to a motor drive system, IEEE Trans. Ind. Electron. 58 (2011) 1625-1633. doi:10.1109/TIE.2010.2098355.

[16] M. Alavi, D. Wang, M. Luo, Short-circuit fault diagnosis for three-phase inverters based on voltage-space patterns, IEEE Trans. Ind. Electron. (2014). doi:10.1109/TIE.2013.2297298.

[17] P. Duan, K.G. Xie, L. Zhang, X. Rong, Open-switch fault diagnosis and system reconfiguration of doubly fed wind power converter used in a microgrid, IEEE Trans. Power Electron. 26 (2011) 816-821. doi:10.1109/TPEL.2010.2095470.

[18] M.N. Soares, J. Gyselinck, Y. Mollet, N. Gioia, Vibration-Based Rotor-Side-Converter Open-Switch-Fault Detection in DFIGs for Wind Turbines, 2018 IEEE Int. Conf. Progn. Heal. Manag. (2018) 1-6.

[19] J. Smajo, D. Vukadinovic, Electromagnetic torque analysis of a DFIG for wind turbines, WSEAS Trans. Syst. 7 (2008) 479-488.

J. John Justo, K.S. Ro, Control strategies of doubly fed induction generator-based wind turbine system with new rotor current protection topology, J. Renew. Sustain. Energy. 4 (2012). doi:10.1063/1.4748808. 